NBER WORKING PAPER SERIES

WAGES, RELATIVE PRICES AND THE CHOICE BETWEEN
FIXED AND FLEXIBLE EXCHANGE RATES

Richard C. Marston

Working Paper No. 793

NATIONAL BUREAU OF ECONOMIC RESEARCH 1050 Massachusetts Avenue

Cambridge MA 02138

October 1981

This paper was written while the author was a visiting professor at the Ecole Superieure des Sciences Economiques et Commerciales. The Marion, Jacques Melitz Marion, Jacques Melitz, Marcus Miller, Stephen Turnovsky, Charles Wyplosz and participants in the Warwick University Summer Workshop on Open Economy Macroeconomics and the NBER Summer Institute on Financial support grant (SES-8006414) is a German Marshall Fund Fellowship and a NSF reported here is part of the International studies. author and not studies. Any opinions expressed are those of the author and not those of the National Bureau of Economic Research. 
WAGES, RETATIVE PRICES AND THE CHOICE BETWEEN FIXED AND FTEXIBIE EXXCHANGE RATES

\begin{abstract}
This paper reexamines the choice between fixed and flexible rates to take into account wage indexation and flexible prices. The model employed is of a small open economy faced by monetary and aggregate behavior in this model varies depending and abroad. Aggregate supply one-period labor contracts or are indexed to whether wages are set in general price level.

Two central conclusions emerge from the analysis. First, for all disturbances the difference in output variation between fixed and flexible rates is dependent upon the degree of wage indexation, being proporeconomy. Thus the more degree of wage indexation in the domestic the choice of exchange rateregimdexed the economy, the less difference the effect of foreign disturbances on the domestit variation. Secondly, much on foreign wage and price behavior the domestic economy depends as the world is fully indexed, flexible rates domestic. If the rest of country completely from foreign mone rates insulate the domestic of the world is more highly indexed thy disturbances. If the rest for high price elasticities at least, a the domestic country, then put variation associated with foreign demand diste rate dampens the out-
\end{abstract} Richard C. Marston Wharton School University of Pennsylvania Philadelphia, PA 19104 (215) $-243-7626$ 
How much difference a flexible exchange rate makes to the economic performance of a country depends significantly on wage behavior. If wages are sufficiently sensitive to exchange rates, flexible rates will exhibit much the same variability of output as a fixed exchange rate regime. Foreign wage behavior is also of key importance, since high wage flexibility abroad can insulate the domestic country from some foreign disturbances regardless of domestic wage behavior, while for other economic disturbances it is the relative degree of wage flexibility that determines the desirability of flexible rates. This paper reexamines the choice between fixed and flexible rates taking into account both domestic and foreign wage behavior.

Wage behavior is important to the choice between exchange rate regimes because it determines to what extent a change in the exchange rate also changes the relative prices of foreign and domestic goods. It is primarily through changes in relative prices that exchange rates affect domestic output and employment. Traditional treatments of fixed and flexible exchange rates, of which Mundell's Canadian Journal study (1963) is the best known, assumed that any change in the exchange rate resulted in an equal change in relative prices because both wages and domestic prices were assumed constant. When wages are responsive to changes in the general price level, however, domestic prices respond indirectly to changes in exchange rates, with correspondingly less effect on relative prices. In such circumstances, as shown earlier by Sachs (1980), changes in exchange rates lead to relatively small changes in real output and employment.

This paper examines the choice between exchange rate regimes for a small country faced by monetary and aggregate demand disturbances originating at home and abroad. For domestic disturbances, the paper uses aggregate demand and supply curves to provide a geometric analysis of how these disturbances 
affect output and prices in both exchange rate regimes. The aggregate demand and supply curves permit a simple interpretation of the original Mundell results and the modification which those results undergo when wages and prices respond to exchanges rates. The supply curve is derived from a wage indexation model similar to that used by Flood and Marion (1980) and others. Ful1 wage indexation corresponds to the fixed real wage case examined earlier by Sachs (1980). For the case of partial indexation, the relative performance of fixed and flexible rates is shown to vary directly with the degree of wage indexation.

Foreign disturbances affect the domestic economy through a variety of channels, so the first step in the analysis of these disturbances is the specification of a model of a foreign economy to determine how foreign output and other variables respond to each disturbance. Foreign monetary and aggregate demand disturbances are studied first within this model, then their effects are traced through the domestic model. The results depend crucially on wage indexation, but here both domestic and foreign levels of indexation are important. For foreign monetary disturbances, the paper shows that the insulative properties of a flexible regime depend less upon domestic than on foreign indexation. And for foreign demand disturbances, the choice between fixed and flexible rates is dependent upon the relative degrees of indexation at home and abroad.

The first section of the paper describes the behavior of the domestic country, including its response to domestic disturbances. The second section of the paper introduces a foreign model for the analysis of foreign disturbances. 
I. DOMESTIC BEHAVIOR

The domestic country trades with the foreign country, representing the rest of the world, but is assumed to be too small to affect the latter. This assumption allows the analysis of foreign disturbances to be conducted in two stages involving the respective countries. ${ }^{1}$ The model of each country consists of three equations, aggregate demand and supply equations for the good produced in that country, and an equation describing financial behavior.

A. The Domestic Model

$$
\begin{aligned}
& Y_{t}=g_{p}\left(P_{t}^{f}+x_{t}-P_{t}\right)+g_{y} Y_{t}^{f}-g_{r}\left(r_{t}-\left({ }_{t}^{E I} I_{t+1}-I_{t}\right)\right)+g_{0}+u_{t}^{d} \\
& (1 a) \quad I_{t}=a_{t}+(1-a)\left(P_{t}^{f}+x_{t}\right) \\
& Y_{t}=c\left(P_{t}-{ }_{t-1} E P_{t}\right)-c \cdot b\left(I_{t}-{ }_{t-1} I_{t}\right)+c_{0} \\
& (2 a) \quad Y_{t}=\left(1-c^{\prime}\right) L_{t}=-c\left(W_{t}-P_{t}\right)+c \cdot \ln \left(1-c^{\prime}\right) \\
& (2 b) \quad W_{t}^{\prime}=t-1 E P_{t}+\ln \left(1-c^{\prime}\right)-c^{\prime} \bar{L} \\
& \text { (2c) } \quad W_{t}=W_{t}^{\prime}+b\left(I_{t}-t-1 E I_{t}\right) \\
& \text { where } c=\left(1-c^{\prime}\right) / c^{\prime} \text { and } c_{0}=\left(1-c^{\prime}\right) \bar{L}
\end{aligned}
$$

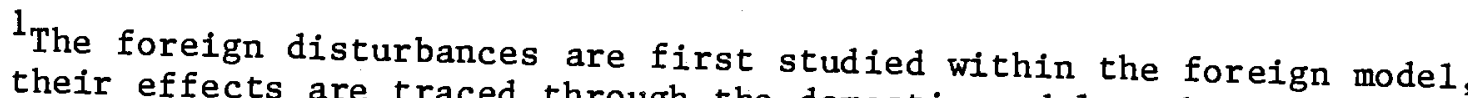
then their effects are traced through the domestic model. This approach, which Flood and Marion (1980) term an extended small country analysis, is preferable to a symmetric two country analysis for studying exchange rate policy for a single country. Not only is it easier to understand (because the faced by most countries which cannot significcords better with the situation faced by most countries which cannot significantly affect foreign an exchange-rate union between the similar two-stage analys is is used to study regions. 
(3)

$$
\begin{aligned}
& M_{t}-I_{t}=\left(P_{t}+Y_{t}-I_{t}\right)-k_{1} \cdot r_{t}+k_{0} \\
& (3 a) \quad r_{t}=r_{t}^{f}+t_{t+1}^{E X}-X_{t} \\
& (3 b) \quad M_{t}=\bar{M}+u_{t}^{m}
\end{aligned}
$$

\section{LIST OF VARIABLES}

A11 variables are in logarithms (except interest rates).

$Y_{t}, Y_{t}^{f}: \quad$ domestic, foreign outputs

$P_{t}, P_{t}^{f}: \quad$ prices of domestic, foreign output

$X_{t}: \quad$ exchange rate (domestic currency price of foreign currency)

$r_{t} ; r_{t}^{f}: \quad$ domestic, foreign interest rates

$I_{t}: \quad$ general price level of the domestic country $t^{E} J_{t+1}: \quad \begin{aligned} & \text { expected value of a variable at } t+1, J_{t+1} \text {, based on information } \\ & \text { available at } t\end{aligned}$

$\mathrm{L}_{\mathrm{t}}: \quad$ units of labor

$w_{t}: \quad$ domestic nominal wage

$\mathrm{W}_{t}^{\prime}: \quad$ contract wage

$M_{t}, M_{t}^{f}: \quad$ domestic, foreign money supplies

$u_{t}^{m}, u_{t}^{d}: \quad$ domestic monetary, aggregate demand disturbances

$u_{t}^{m f}, u_{t}^{d f}: \quad$ foreign monetary, aggregate demand disturbances

Equation (1) describes aggregate demand for the domestic good as a function of the relative prices of foreign and domestic goods, foreign output 
(which affects export demand), the real interest rate, and a stochastic disturbance with a mean of zero and serially uncorrelated. A rise in the foreign price relative to the domestic price (a fall in the terms of trade) is assumed to increase aggregate demand as is a rise in foreign output, ${ }^{2}$ while a rise in the real interest rate is assumed to reduce aggregate demand. 3 In the case of perfect substitution between foreign and domestic goods, where $g_{p}$ becomes infinite in size, this aggregate demand equation reduces to the familiar purchasing power parity relationship.

Supply behavior is based on a labor contract lag of one period with the partial or complete indexation of wages to current prices. The supply equation (2) takes a more complicated form than in a closed economy because there are two prices involved in supply decisions, the price of domestic output $\left(P_{t}\right)$ and the general price level $\left(I_{t}\right)$, the latter a weighted average of domestic and foreign prices. (See equation la). Output is responsive to nominal wages relative to the price of domestic output, but nominal wages may be at least partially indexed to current changes in the general price level. With indexation, supply is a function of two price prediction errors. (See equation 2).

This supply equation is derived from a Cobb-Douglas production function (2a), a labor market equilibrium condition ( $2 b)$ determining the contract wage, $\mathrm{W}_{t}{ }^{\prime}$, and a wage indexation equation (2c). The contract wage, reflecting expectations at $t-1$, is based on labor demand (derived from the production

2 The Marsha11-Lerner condition is assumed to hold, so the price elasticity, $g_{p}$, must be positive.

${ }^{3}{ }_{t}^{E I_{t+1}}-I_{t}$ is the expected change in the general price level based on information available at time $t$. The expectation $t^{E I} t+1$ is assumed to be formed rationally from the rest of the model. 
function) and an inelastic labor supply $(\overline{\mathrm{L}}) .4$ The actual wage, $W_{t}$, will differ from the contract wage if the indexation parameter, $b$, is different from zero; this parameter is assumed to vary between zero (no indexation) and one (full indexation). 5 with no indexation, only domestic price prediction errors matter, but with full indexation, price prediction errors in the general price index also matter. With full indexation, in fact, equal increases in $P_{t}$ and $I_{t}$ leave supply unaffected. When indexation is less than complete, however, equal increases in $P_{t}$ and $I_{t}$ increase supply since the real wages faced by producers fall.

The domestic country has two financial assets, money and a bond bearing interest rate $r_{t}$. In equation (3), the demand for money is expressed as a function of real income, with money balances and income being deflated by the general price level, as well as the domestic interest rate. ${ }^{6}$ As in the

${ }^{4}$ The desired labor supply is inelastic, but once the contract is signed the amount of labor supplied is determined by the demand for 1 abor as in Gray (1976). The desired labor supply, alternatively, might be sensitive to nominal wages relative to the general price level. None of the results below would be affected by this change in specification, since current output would be a function of the same price prediction errors as in (2). When labor supply is variable, however, an alternative objective function measuring deviations of output from desired output is no longer equivalent to our objective function. (See Section I-B below).

5 For studies of wage indexation behavior, see Fischer (1977), Gray (1976), Modigliani and Padoa-Schioppa (1978), and as previously mentioned, Sachs (1980) and Flood and Marion (1980). The study by Flood and Marion also analysed the choice between fixed and flexible exchange rates in the presence of domestic and foreign disturbances, but in a model where purchasing power parity holds. Their analysis assumed that the indexation parameter is an endogenous variable set at its optimal value in each exchange rate regime. Here we will assume that because of institutional or legal constraints, the degree of indexation remains the same when the exchange rate regime changes. Thus the analysis will show how the choice of exchange rate regime differs between countries with different types of wage and price behavior.

6 The income elasticity of the demand for money is assumed to be equal to one. If it is not equal to one, a change in the general price level, and therefore the exchange rate, will have an effect on the net demand for money proportional to one minus this elasticity. In that case, the well-known 
earlier Mundell analysis, the domestic bond is assumed to be a perfect substitute for the foreign bond, so the expected returns on the two bonds are equal. (See equation $3 a$ ).

The behavior of the money supply depends upon the exchange rate regime. Under flexible rates, the money supply is assumed to be exogenously determined as in equation (3b). The current money supply is equal to a base level plus a random term, where the latter has a mean of zero and is serially uncorrelated as well as uncorrelated with the demand disturbance. The supply of money under fixed rates is determined endogenously by exchange market intervention; that is, $M_{t}$ adjusts to keep $X_{t}$ fixed.

The equations of the domestic model, (1) - (3), determine three variables: domestic output, the price of that output, and the exchange rate, as functions of the domestic disturbances. In this section, only domestic disturbances are to be considered, so for convenience we assume that the foreign output, price, and interest rate are constant. To facilitate comparison between the two exchange rate regimes, equations (1) and (2) are first solved for $Y_{t}$ and $P_{t}$ as functions of $X_{t}$ and the aggregate demand disturbance, $u_{t}^{d}$. The resulting expressions, equations (4) and (5) below, describe demand and supply behavior in both exchange rate regimes: 7

$$
Y_{t}-\bar{Y}=\frac{c(1-a \cdot b)}{D_{1}} \cdot u_{t}^{d}+\frac{\left(g_{p}+g_{r} a\right) c(1-b)}{D_{1}}\left(x_{t}-\bar{X}\right)
$$

\footnotetext{
Mundell result that under flexible rates fiscal policy is ineffective in raising output breaks down even without taking into account the expectations effect considered below. Henderson (1981) discusses this issue.

$7 \bar{Y}, \bar{P}$ are the solutions for $Y_{t}$ and $P_{t}$ when the disturbances in equations (1) and (2) are equal to zero. Similarly, $\bar{x}$ is the solution for $X_{t}$ when the disturbances in all three equations, (1) - (3), are equal to zero.
} 
(5)

$$
\begin{aligned}
& P_{t}-\bar{P}=\frac{u_{t}^{d}}{D_{1}}+\frac{\left(g_{p}+g_{r} a+c \cdot b(1-a)\right)}{D_{1}}\left(x_{t}-\bar{x}\right) \\
& x_{t}-\bar{x}=-\frac{(1+c(1-a \cdot b))}{D} u_{t}^{d}+\frac{D_{1}}{D} u_{t}^{m} \\
& D_{1}=g_{p}+g_{r} a+c(1-a b)>0 \\
& D=\left(1+k_{1}\right) D_{1}+c(1-b)\left(g_{p}+g_{r} a-1\right)>0
\end{aligned}
$$

Under fixed rates, $x_{t}$ is kept equal to $\bar{x}$. Under flexible rates, $x_{t}$ can be expressed as in equation (6) as a function of both domestic disturbances, $u_{t}^{d}$ and $u_{t}^{m}$, by solving all three equations, (1) - (3), for the reduced form.

\section{B. Domestic Disturbances}

The two domestic disturbances in the model, $u_{t}^{d}$ and $u_{t}^{m}$, need further discussion. Following Mundell (1963) and other studies of Internal-external balance, we might view these factors as deliberate instruments of fiscal and monetary policies, respectively. Given the stochastic assumptions adopted in this paper, these policies would have to be unanticipated and temporary. ${ }^{8}$ We prefer to view the factors as economic disturbances, however, and to regard the task of policy to minimize the effects of these disturbances. The choice between fixed and flexible rates is based on which regime minimizes the

8 The disturbances have an expected value of zero and are serially uncorrelated. For an analysis of fiscal policy in a stochastic framework similar to this paper's, see Marion (1981) where the distinctions between unanticipated and anticipated, as well as temporary and permanent policies are spelled out clearly. Eaton and Turnovsky (1981) similarly examine different types of monetary policy in an interesting analysis showing how imperfect substitutability between assets alters the effectiveness of monetary policy. 
effects of the disturbances on domestic output. More specifically, we examine the effects of the disturbances on the variance of output in each regime. 9 The reader, however, may easily reinterpret the results to determine the relative effectiveness of policies under fixed and flexible rates.

We begin by examining the effects of the disturbances in the case where there is no wage indexation in the domestic economy, then we consider the effects of indexation. When there is no wage indexation, the effects of both disturbances correspond closely to those reported in Munde11's study (1963). A monetary disturbance, representing an increase in the money supply $\left(u_{t}^{m}>0\right)$, has no effect on output under fixed exchange rates but simply results in an offsetting capital flow. In a flexible regime, in contrast, a monetary expansion leads to a depreciation of the domestic currency and to an increase in output as we11 as in the domestic price.10 Thus, as in Munde11's study, domestic monetary disturbances cause variations in output only under flexible exchanges rates.

An aggregate demand disturbance, in contrast, leads to greater changes in output under fixed rates. An increase in aggregate demand raises both domestic output and the domestic price. Under flexible rates, the increase in domestic transactions leads to an appreciation of the domestic currency which

${ }^{9}$ Following Gray (1976) we might measure domestic output relative to "desired" output, rather than expected output, where the former is defined as that output which would prevail in a frictionless economy without contract lags. As long as labor supply is inelastic, these two objectives are equivalent since desired output, like expected output, is unaffected by the disturbances.

10 The monetary disturbance affects output and the domestic price only through the exchange rate, as equations (4) and (5) indicate. The exchange rate depreciates, $x_{t}-\vec{x}>0$, so output and the domestic price both increase under flexible rates. 
dampens or modifies the overall increase in aggregate demand. 11 Thus there is less output variation as well as price variation under flexible rates. When indexation is complete $(b=1)$, however, these familiar results break down. To understand why this is true, notice that the effect of the exchange rate on domestic output is dependent on the degree of indexation in the domestic economy. As equation (4) indicates, the effect is proportional to $c(1-b)$, with full indexation $(b=1)$ preventing the exchange rate from affecting domestic output at all. For that reason, the difference in output variation between the two regimes must be proportional to $c(1-b)$. And with full indexation, each disturbance must have an identical effect on output in the two regimes. These results can be illustrated by examining Figures 1 and 2 showing how aggregate demand and supply adjust to the disturbances when indexation is complete.

First consider the monetary disturbance. Under flexible rates, the resulting depreciation leads to an outward shift in the aggregate demand function (to point $B$ in Figure 1) because of the sensitivity of aggregate demand to relative prices and the real interest rate. When wages are fully indexed to the general price level, however, there is a corresponding leftward shift in aggregate supply (to point $C$ ) because the depreciation leads to a rise in the nominal wage. The price of domestic output accordingly rises

${ }^{1} 1_{\text {Under }}$ flexible rates, the direct (positive) impact of $u_{t}^{d}$ on $Y_{t}$ in equation (4) is modified by the fall in $X_{t}$ (which reduces $Y_{t}$ ). Output nonetheless increases even under flexible rates. In contrast, Mundell's study of fixed and flexible rates showed that output did not increase at all in response to a demand disturbance (in his study, an increase in government spending); given his assumption that exchange rate expectations were static, only a constant output was consistent with money market equilibrium. In this study, an appreciation of the exchange rate leads to a change in the expected exchange rate and therefore to a change in the domestic interest rate, so output can increase despite a constant money supply. 


\section{$10 a$}

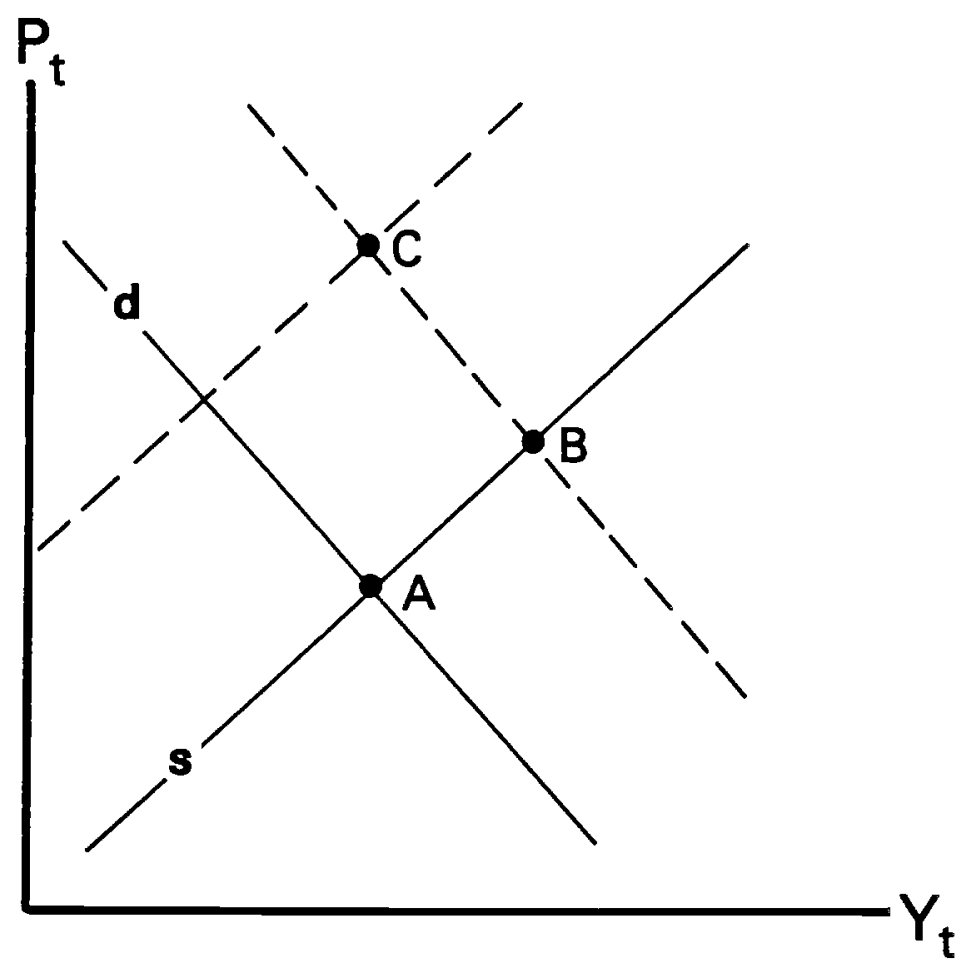

FIGURE 1. DOMESTIC MONETARY DISTURBANCE 
further; in fact, the price of domestic output and the exchange rate increase by the same amount, with the constant terms of trade ensuring that output remains fixed at its original level. ${ }^{12}$ Under fixed rates, in contrast, no depreciation occurs, so the aggregate supply and demand curves remain at point A. With full indexation of wages, therefore, the monetary disturbance leaves output unaffected in both regimes. The two regimes differ with respect to price behavior, however, since prices increase only under flexible rates. The aggregate demand disturbance does change real output in both regimes. Under fixed rates, the demand disturbance shifts equilibrium to point $A^{\prime}$ in Figure 2. Under flexible rates, the increase in demand leads to an appreciation of the franc and to a smaller increase in aggregate demand than under fixed rates (to point $\mathrm{B}^{\prime}$ ). With complete indexation of wages, however, the appreciation of the exchange rate also raises aggregate supply by lowering real wages faced by producers. Point $C^{\prime}$ is reached where the change in output is the same as under fixed rates. 13 Thus, as in the case of a monetary disturbance, full indexation results in the same variance of output under fixed and flexible regimes. In both cases, indexation ensures that the

${ }^{12}$ Sachs (1980) and Flood and Marion (1980) also discuss this case of full indexation. In the model specified by Sachs, a constant terms of trade ensures that the disturbance has no net effect on aggregate demand. In the present model, aggregate demand is also a function of expectations through the real interest rate. But because the expected change in the exchange rate is equal to the expected change in the domestic price as well as in the general price level, the real interest rate also remains constant.

13 Whether $P_{t}$ changes more under fixed or flexible rates when $b=1$ cannot be established without additional restrictions on the parameters. $P_{t}$ increases under fixed rates, but declines under flexible rates (as long as $\left.k_{1}<c(1-a)\right)$. The change in $P_{t}$ is greater (in absolute value) under fixed rates if $2\left(1+k_{1}\right)>[1+c(1-a)]$. This inequality can be reversed if output is sufficiently responsive to the real wage (as reflected in c). (Both of these inequalities are easily derived from equations (5) - (6)). 
lla

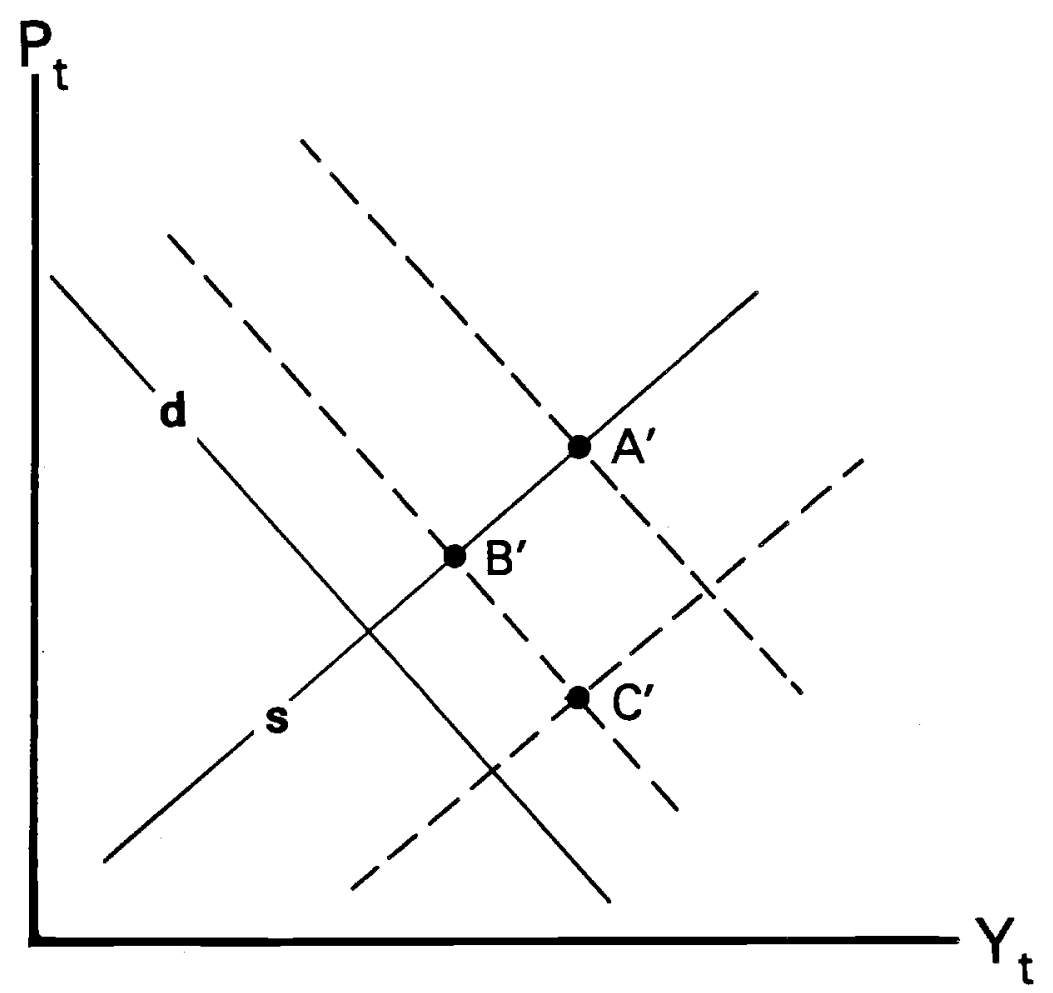

FIGURE 2. DOMESTIC AGGREGATE DEMAND DISTURBANCE 
shift in aggregate demand due to the exchange rate is matched by an offsetting shift in aggregate supply, so that the exchange rate has no net effect on domestic output.

In the absence of indexation, exchange rate flexibility is preferred in the case of the aggregate demand disturbance but fixed rates are preferred in the case of the monetary disturbance. The effect of indexation is to blur these differences, with full indexation eliminating the advantages or disadvantages of flexibility in modifying output changes.

II. FOREIGN DISTURBANCES

How foreign disturbances affect the domestic economy depends upon foreign wage and price behavior as well as domestic. The degree of wage indexation in the rest of the world is important in determining the insulative properties of a flexible regime in the case of foreign monetary disturbances, and in determining the relative advantage of flexible rates in the case of foreign aggregate demand disturbances.

To examine the impact of foreign disturbances on the domestic economy, we must first analyze how the foreign economy responds to these disturbances. Three variables are particularly important: the foreign price, output and interest rate. All three variables provide channels through which the disturbances affect the domestic economy.

\section{A. The Foreign Model}

(1)' $\quad Y_{t}^{f}=g_{0}^{f}-g_{r}^{f}\left(r_{t}^{f}-\left({ }_{t}^{E P_{t+1}^{f}}-P_{t}^{f}\right)\right)+u_{t}^{d f}$

(2)' $\quad Y_{t}^{f}=c_{0}^{f}+c^{f}\left(1-b^{f}\right)\left(P_{t}^{f}-{ }_{t-1} E P_{t}^{f}\right)$

(3)' $\quad M_{t}^{f}=\bar{M}^{f}+u_{t}^{m f}=P_{t}^{f}+Y_{t}^{f}-k_{1} \cdot r_{t}^{f}+k_{0}$ 
The model parallels that one specified for the domestic country, with equations for aggregate demand and supply and for the financial sector. The main difference is that only one good is involved, so there are no relative prices entering the model. Aggregate supply, therefore, is a function of the price of the foreign good alone; output responds to unexpected changes in that price as long as there is less than complete indexation ( $b^{f}$ is less than one). Note that for convenience the money demand function is assumed to have the same income and interest rate elasticities as the domestic country.

The three equations can be solved for $\mathrm{P}_{t}^{f}, \mathrm{Y}_{t}^{\mathrm{f}}$, and $\mathrm{r}_{t}^{\mathrm{f}}$ as functions of the foreign disturbances, $u_{t}^{m f}$ and $u_{t}^{d f} \cdot 14$

$$
\begin{aligned}
& P_{t}^{f}-\bar{P}^{f}=\frac{u_{t}^{m f}}{F_{1}}+\frac{u_{t}^{d f}}{F_{2}} \\
& Y_{t}^{f}-\bar{Y}^{f}=c^{f}\left(1-b^{f}\right)\left(\frac{u_{t}^{m f}}{F_{1}}+\frac{u_{t}^{d f}}{F_{2}}\right) \\
& r_{t}^{f}-\bar{r}^{f}=-\left(1+\frac{c^{f}\left(1-b^{f}\right)}{g_{r}^{f}}\right) \frac{u_{t}^{m f}}{F_{1}}+\left(1+c^{f}\left(1-b^{f}\right)\right) \frac{u_{t}^{d f}}{k_{1} F_{2}}
\end{aligned}
$$

where $\quad F_{1}=1+k_{1}+c^{f}\left(1-b^{f}\right)+k_{1} \cdot c^{f}\left(1-b^{f}\right) / g_{r}^{f}>0$

$$
F_{2}=F_{1} g_{r}^{f} / k_{1}>0
$$

All three variables are affected by both foreign disturbances, although foreign output remains constant if there is full indexation abroad $\left(b^{f}=1\right)$.

${ }^{14} \overline{\mathrm{P}}^{\mathrm{f}}, \overline{\mathrm{Y}}^{\mathrm{f}}, \overline{\mathrm{r}}^{\mathrm{f}}$ are the solutions of the foreign model when both disturbances are equal to zero. 
B. Foreign Monetary Disturbances

A foreign monetary disturbance, representing an increase in the money supply abroad $\left(u_{t}^{m f}>0\right)$, leads to a rise in foreign prices and output and to a fall in the foreign interest rate. The effect on the domestic economy is summarized below in the following equations:

(4)'

$$
\begin{aligned}
& \text { (4)' } \quad Y_{t}-\bar{Y}= \frac{c(1-a b)}{D_{1}}\left(g_{y}+g_{r} / g_{r}^{f}\right) \cdot c^{f}\left(1-b^{f}\right) \frac{u_{t}^{m f}}{F_{1}}+ \\
& \frac{\left(g_{p}+g_{r} a\right) c(1-b)}{D_{1}}\left(\frac{u_{t}^{m f}}{F_{1}}+\left(x_{t}-\bar{X}\right)\right) \\
& \text { (5)' } \quad P_{t}-\bar{P}=\frac{\left(g_{y}+g_{r} / g_{r}^{f}\right)}{D_{1}} \cdot c^{f}\left(1-b^{f}\right) \frac{u_{t}^{m f}}{F_{1}}+ \\
& \frac{\left(g_{p}+g_{r} a+c b(1-a)\right)}{D_{1}}\left(\frac{u_{t}^{m f}}{F_{1}^{m}}+\left(x_{t}+\bar{X}\right)\right)
\end{aligned}
$$

(6)' $\quad x_{t}-\bar{x}=-\frac{\left(D_{2}\left(g_{y}+g_{r} / g_{r}^{f}\right)+D_{1} k_{1} / g_{r}^{f}\right)}{D} \cdot c^{f}\left(1-b^{f}\right) \cdot \frac{u_{t}^{m f}}{F_{1}}-\frac{u_{t}^{m f}}{F_{1}}<0$

$$
D_{2}=1+c(1-a b)>0
$$

Domestic output and price both increase under fixed rates. (Both terms in (4)' and (5)' are positive if $x_{t}$ is fixed). The domestic currency appreciates under flexible rates, so exchange rate flexibility tends to dampen the domestic expansionary effects of the foreign disturbance. In fact, the appreciation can lead to a net reduction in domestic output, as we shall see below.

How the foreign monetary expansion affects the domestic economy depends partly upon the degree of indexation abroad. Consider first the special case 
where there is full indexation abroad $\left(b^{f}=1\right)$. The foreign monetary disturbance then has no effect on foreign output (so the first terms in equations $(4)^{\prime}-(6)^{\prime}$ are equal to zero). Only foreign nominal variables are affected, with the foreign price rising and the foreign interest rate falling. Under fixed exchange rates, domestic output must rise. Under flexible rates, however, domestic output is completely insulated from this disturbance as is the domestic price; the appreciation of the domestic currency neutralizes the changes in the nominal variables. 15

If wage indexation is less than complete abroad, however, this monetary disturbance raises foreign output as well as the foreign price. Despite originating as a monetary disturbance, it becomes both a real and nominal disturbance from the point of view of the domestic country. The real disturbance, representing the change in foreign output, affects the domestic economy much as would a domestic aggregate demand disturbance; it raises demand for the domestic good (proportionally to $g_{y}$ in the first terms of equations (4)' and (5)').16 The nominal disturbance, representing the combined effect of a higher foreign price and an appreciating exchange rate, reduces demand for the domestic good. That is because the appreciation is always large enough to ensure that the domestic currency price of the foreign good falls. 17 The net result of a higher foreign output and an appreciating exchange rate can be either a rise or fall in domestic output.

${ }^{15}$ In equations (4)' and (5)', the second terms are equal to zero, since the exchange rate appreciates by $x_{t}-\bar{x}=-u_{t}^{m f} / F_{1}$.

16 The fall in the foreign interest rate reinforces the effect of higher foreign output on domestic aggregate demand (proportionally to $g_{r}$ ).

${ }^{17}$ That is, $\left(P_{t}^{f}-\bar{P}^{f}\right)+\left(x_{t}-\bar{X}\right)=\left[u_{t}^{m f} / F_{1}+\left(x_{t}-\bar{X}\right)\right] \leq 0$, with the domestic currency price remaining constant only if $b^{f}=1$. 
In these circumstances, full wage indexation at home does not insulate domestic output from the disturbance since it cannot prevent the real disturbance from affecting domestic output. Instead, it has the unfortunate effect of preventing the appreciation from dampening aggregate demand. Indeed, full indexation ensures that domestic output varies as much under flexible rates as under fixed rates. Ironically enough, it is full indexation abroad rather than at home that provides effective insulation.

Partial rather than full indexation in preferable under flexible rates. In fact, there is an optimal degree of indexation $(\hat{b})$ which keeps output constant in the face of this disturbance:

$$
\hat{b}=\frac{\left(g_{p}-\left(g_{y} g_{r}^{f}+g_{r}\right)\right)}{\left(g_{p}-\left(g_{y} g_{r}^{f}+g_{r}\right)\right)+\frac{\left(1+k_{1}\right)}{k_{1}}(1-a)\left(g_{y} g_{r}^{f}+g_{r}\right)}
$$

$\hat{b}$ is equal to one only if $g_{p}$ is infinite, the case of perfect substitution between domestic and foreign goods. Otherwise $\hat{b}$ is less than one, with the fraction falling as the price elasticity declines. 18

As far as the choice between fixed and flexible rates is concerned, flexible rates generally exhibit less output variation than fixed rates, but it is possible for the opposite to be true. Recall that domestic output is affected by two conflicting forces: the rise in foreign output raises domestic aggregate demand, while the appreciation of the exchange rate lowers demand. The relative importance of the appreciation increases as the price elasticity $\left(g_{p}\right)$ rises. For high price elasticities, the effect of the positive.

${ }^{18}$ Note that we assume $k_{1}<\left(1+k_{1}\right)(1-a)$, so the denominator of $b$ is 
appreciation may be so large that domestic output falls more under flexible rates than it rises under fixed rates.

The case of perfect substitution (where $g_{p}$ is infinite) illustrates this possibility well. In this case, equations $(4)^{\prime}$ and $(6)^{\prime}$ reduce to the following:

$$
\begin{aligned}
& \text { (4)' } \quad Y_{t}-\bar{Y}=c(1-b)\left(\frac{u_{t}^{m f}}{F_{1}}+\left(x_{t}-\bar{X}\right)\right) \\
& (6)^{\prime} \quad x_{t}-\bar{X}=-\frac{k_{1} \cdot c^{f}\left(1-b^{f}\right)}{g_{r}^{f} \cdot\left(1+k_{1}+c(1-b)\right)} \frac{u_{t}^{m f}}{F_{1}}-\frac{u_{t}^{m f}}{F_{1}}
\end{aligned}
$$

As these equations indicate, domestic output rises in response to a foreign monetary expansion if exchange rates are fixed, but falls if exchange rates are flexible (since $u_{t}^{m f} / F_{1}+\left(x_{t}-x\right)<0$ ) because of the contractionary effect of the appreciation. 19 The change in domestic output under flexible rates is larger rather than smaller in absolute value if $k_{1} \cdot c^{f}\left(1-b^{f}\right)>$ $g_{r}^{f}\left(1+k_{1}+c(1-b)\right)$. This inequality can be satisfied if there is low indexation abroad (i.e., $\left(1-b^{f}\right)$ large) and low sensitivity of foreign demand to the real interest rate $\left(g_{r}^{f}\right.$ smal1), since then the change in the foreign interest rate, and therefore the exchange rate, is relatively large. But otherwise, the superiority of flexible rates is retained even with infinite price sensitivity. 20

19 Notice that when perfect substitution prevails, full indexation at home shields output from the disturbance under flexible rates, the result arrived at earlier, as well as under fixed rates.

${ }^{20}$ Alternatively, we might compare the two regimes assuming that optimal indexation has been adopted in each case, the type of comparison which Flood and Marion made. Full indexation $(b=1)$ is optimal under fixed rates because it reduces the effects of both higher foreign output and prices. But even with optimal indexation, output variation is zero under fixed rates only in 


\section{Foreign Aggregate Demand Disturbances}

In the case of foreign aggregate demand disturbances, there is no longer a presumption in favor of flexible rates, since the choice between regimes depends upon the relative degrees of domestic and foreign indexation as well as other factors.

An increase in aggregate demand abroad $\left(u_{t}^{d f}>0\right)$ leads to a rise in foreign output, the foreign price, and the foreign interest rate. (See equations (7) - (9)). Under fixed exchange rates, the rise in the foreign output and price raises domestic output, but the rise in the foreign interest rate lowers domestic output through the real interest rate effect on aggregate demand. So whether output increases or decreases even under fixed exchange rates is ambiguous. In order to avoid this ambiguity so that we can focus on the foreign output and price effects of this disturbance, we assume at the outset that the real interest rate effect is zero $\left(g_{r}=0\right) .21$ In that case the impact of the disturbance on the domestic economy is summarized by the following equations:

(4)" $\quad Y_{t}-\bar{Y}=\frac{c(1-a b) g_{y}}{D_{1}} c^{f}\left(1-b^{f}\right) \frac{u_{t}^{d f}}{F_{2}}+\frac{g_{p} c(1-b)}{D_{1}}\left(\frac{u_{t}^{d f}}{F_{2}}+\left(x_{t}-\bar{X}\right)\right)$
(5)" $\quad P_{t}-\bar{P}=\frac{g_{y}}{D_{1}} c^{f}\left(1-b^{f}\right) \frac{u_{t}^{d f}}{F_{2}}+\frac{\left(g_{p}+c b(1-a)\right)}{D_{1}}\left(\frac{u_{t}^{d f}}{F_{2}}+\left(x_{t}-\bar{x}\right)\right)$ the limiting cases $b^{f}=1$ and $g_{p}=\infty$ considered above. Flexible rates are therefore superior to fixed rates since as shown above there is no output variation under flexible rates when the optimal $b$ is chosen.

21 Mundell's (1964) analysis of fiscal policy in a two country model encounters a similar ambiguity. Note that the foreign interest rate still affects domestic output under flexible rates by influencing the exchange rate. 
(6)" $\quad x_{t}-\bar{x}=\left(\left[c^{f}\left(1-b^{f}\right)-c(1-b)\right]\left(g_{p}-1\right)+\left(1-g_{y}\right) D_{2} c^{f}\left(1-b^{f}\right)\right) \frac{u_{t}^{d f}}{F_{2} D}<0$

Under fixed rates $\left(x_{t}=\bar{X}\right)$, the foreign demand disturbance raises domestic output and the price of the domestic good. Flexible rates would be preferred to fixed rates if the exchange rate appreciated in response to this

disturbance. But it is evident from the expression for $x_{t}-\bar{x}$ that either a depreciation or appreciation is possible.

Two sets of factors are especially important in determining the movement of the exchange rate, the degrees of indexation at home and abroad $\left(b, b^{f}\right)$ and the sensitivity of aggregate demand to relative prices as reflected in the price elasticity $\left(g_{p}\right)$. In order to investigate the influence of indexation on the choice between regimes, we will consider two polar cases of full wage indexation abroad $\left(b^{f}=1\right)$ and at home $(b=1)$. The analysis will show that the choice between regimes depends crucially upon whether or not the domestic country has a high price elasticity. A high price elasticity, however, has an opposite effect on the exchange rate depending upon whether there is full indexation abroad or at home. This suggests that the choice between regimes also depends upon which country is more highly indexed; the general condition which is presented below confirms this.

Consider first the special case where indexation is complete abroad $\left(b^{f}=1\right)$. An increase in foreign aggregate demand then has no effect on foreign output, but raises the foreign price by $\mathrm{P}_{t}^{\mathrm{f}}-\overline{\mathrm{P}}^{\mathrm{f}}=u_{t}^{\mathrm{df}} / \mathrm{F}_{2}$, with a proportional increase in the foreign interest rate. Under fixed rates, domestic output and price respond to this purely nominal disturbance by rising in proportion to the increase in foreign prices. (See the second terms of (4)" and (5)"). Note that the effect of foreign prices on $Y_{t}$ and $P_{t}$ increases as the price elasticity, $g_{p}$, rises. 
In this case of full indexation abroad, the disturbance has two influences on the exchange rate: the higher foreign interest rate leads to a depreciation of the home currency, while the higher domestic interest rate due to the increase in domestic transactions leads to an appreciation. How much the domestic interest rate increases depends upon the price elasticity, $g_{p}$, since a high price elasticity implies a greater increase in the domestic output and price. The home currency appreciates if and only if this price elasticity exceeds unity: 22

$$
\mathrm{g}_{\mathrm{p}}>1
$$

If the home currency appreciates, then domestic output increases less under flexible rates than under fixed rates. If the inequality is reversed, the home currency depreciates and so fixed rates exhibit less variability of output.

When $b^{f}$ is less than one, the disturbance raises both foreign output (by $c^{f}\left(1-b^{f}\right) u_{t}^{d f} / F_{2}$ ) and the foreign price (by $\left.u_{t}^{d f} / F_{2}\right)$. So the foreign demand disturbance affects the domestic economy through both real and nominal channels. Domestic output rises under fixed rates, but under flexible rates the effect on the exchange rate, and therefore on output, varies depending upon the price elasticity as before.

Consider a second special case where domestic indexation is complete $(b=1)$. Two results familiar from the earlier analysis emerge. Full

${ }^{22}$ Under fixed rates, the foreign interest rate rises by $r_{t}^{f}-\vec{r}^{f}=$ $u_{t}^{d f} / k_{1} F_{2}$, while the domestic interest rate rises by

$$
r_{t}-\bar{r}=\frac{\left(P_{t}-\bar{P}\right)+\left(Y_{t}-\bar{Y}\right)}{k_{1}}=\left[1+\frac{\left(g_{p}-1\right) c(1-b)}{D_{1}}\right] \frac{u_{t}^{d f}}{k_{1} F_{2}}
$$

If $\mathrm{g}_{\mathrm{p}}>1$, then the domestic interest rate rises more than the foreign interest rate; thus under flexible rates, the domestic currency appreciates. But if $g_{p}<1$, a depreciation occurs. 
indexation cuts off the nominal channel, so domestic output does not respond to changes in the foreign price or exchange rate. (The second term in (4)" is equal to zero). Secondly, output nonetheless rises because the real channel is still important despite the indexation. Yet because the exchange rate has no effect on domestic output, the latter changes by the same amount under both fixed and flexible exchange rates.

The case of $b=1$ is interesting per se, but also because it shows what happens to the exchange rate when the domestic country is more fully indexed (in this case, perfectly indexed) than the forelgn country. Now the domestic currency depreciates when the price elasticity is high. That is because a higher price elasticity reduces the impact of foreign output on domestic transactions. (Note that in the first terms of (4)" and (5)" only the denominators are a function of $g_{p}$ ). Hence the disturbance has correspondingly less effect on the domestic interest rate. Assume for the present that $g_{y}=1,23$ in which case only the price elasticity matters in determining which way the exchange rate moves (1.e., the last term of (6)" is equal to zero). Then the domestic currency depreciates if and only if

$$
g_{p}>1
$$

Thus when there is full indexation at home, a depreciation occurs under the same circumstances as an appreciation when there is full indexation abroad. Because the foreign demand disturbance has opposite effects on the exchange rate when indexation is high at home rather than abroad, the relative

${ }^{23} \mathrm{~g}_{\mathrm{y}}$ is an elasticity measuring the percent change in domestic aggregate demand in response to a one percent change in foreign output. We assume that $g_{y}=1$, but later consider the case where $g_{y} \neq 1$. The appendix of Marston (1981) shows how this elasticity is related to a more traditional export demand elasticity. 
degrees of indexation at home and abroad are clearly important in the choice between regimes. The proposition below shows how indexation affects this choice:

If the home country has a high price elasticity $\left(g_{p}>1\right), 24$ then a foreign demand disturbance has less effect upon domestic output under flexible rates if and only if

$$
c^{f}\left(1-b^{f}\right)<c(1-b)
$$

If wage indexation is lower at home than abroad, the domestic currency appreciates in response to the demand disturbance abroad. 25 The appreciation dampens the rise in output at home, so flexible rates are superior. If wage indexation is lower abroad, a depreciation occurs, exacerbating the effects of the disturbance on domestic output. So a country with a relatively high degree of indexation should prefer fixed rates to flexible.

The importance of the relative degrees of indexation can be shown most simply in the case of perfect substitution between domestic and foreign goods ( $g_{p}$ infinite). Under fixed rates, prices, outputs, and interest rates respond as follows to the disturbance:

$$
\begin{gathered}
P_{t}-\bar{P}=P_{t}^{f}-\bar{P}^{f}=u_{t}^{d f} / F_{2} \\
Y_{t}-\bar{Y}=c(1-b) \cdot u_{t}^{d f} / F_{2} \\
r_{t}-\bar{r}=(1+c(1-b)) \frac{u_{t}^{f f}-\bar{Y}_{t}^{f}=c^{f}\left(1-b^{f}\right) u_{t}^{d f} / F_{2}}{k_{1} F_{2}} \\
r^{f}-\bar{r}^{f}=\left(1+c^{f}\left(1-b^{f}\right)\right) \frac{u_{t}^{d f}}{k_{1} F_{2}}
\end{gathered}
$$

${ }^{24}$ We continue to assume that the foreign output elasticity is equal to one $\left(g_{\mathrm{y}}=1\right)$.

${ }^{25}$ Differences in the production parameters, $c$ and $c^{f}$, could also account for the change in the exchange rate. We assume in this section that these parameters are equal, although the condition could alternatively be interpreted in terms of these parameters. 
By comparing the changes in interest rates, we can establish that the exchange rate appreciates and therefore dampens domestic output if and only if $c^{f}\left(1-b^{f}\right)<c(1-b) .26$ If the foreign country is more highly indexed, the foreign disturbance leads to an appreciation of the domestic currency because foreign output responds less to the disturbance than domestic output, and as a result the foreign interest rate rises less than the domestic interest rate. Thus the home country should choose flexible rates. If the home country is more highly indexed, it should elect fixed rates. Note that if the home and foreign countries have the same degree of indexation, no change in the exchange rate occurs, so output variation is identical in the two regimes. These conclusions are modified if the elasticity of foreign output in the aggregate demand equation is different from unity. If $g_{y}<1$, then there is a bias toward depreciation since increases in foreign output have less than proportional effects on domestic aggregate demand (thereby raising the domestic interest rate less). On the other hand, if $\mathrm{g}_{\mathrm{y}}>1$, there is a bias toward appreciation. But a higher price elasticity reduces the importance of this factor (and when $g_{p}$ is infinite, the influence of $g_{y}$ becomes negligible). Secondly, these conclusions are reversed when there are low price elasticities $\left(g_{p}<1\right)$, as the discussion above has indicated. Then flexible rates are superior when wage indexation is higher at home than abroad. Thus there is an important interrelationship between price sensitivity and the relative degrees of indexation, as the expression for the exchange rate (6)" indicates.

${ }^{26}$ In the case of perfect substitution, no assumption is necessary about either $g_{r}$ or $g_{y}$ since neither enters the solution for domestic output. 
III. CONCLUDING REMARKS

This paper has reexamined the relative performance of flexible exchange rates to take into account wage indexation and flexible prices. Two central conclusions emerge from the analysis. First, for all disturbances the difference in output variation between fixed and flexible rates is crucially dependent on the degree of wage indexation, being proportional to $(1-b)$. Thus the more highly indexed the economy, the less difference the choice of exchange rate regime makes for output variation. With full indexation, output variation is identical in the two regimes. Secondly, the effect of foreign disturbances on the domestic economy depends as much on foreign wage and price behavior as domestic. If the rest of the world is fully indexed, flexible rates insulate the domestic country completely from foreign monetary disturbances. If the rest of the world is more highly indexed than the domestic country, then for high price elasticities at least, a flexible rate dampens the output variation associated with foreign demand disturbances. 
REFERENCES

Eaton, Jonathan, and Stephen J. Turnovsky (1981) "Effects of Monetary

Disturbances on Exchange Rates with Risk Averse Speculation," unpublished paper.

Fischer, Stanley (1977) "Wage Indexation and Macroeconomic Stability," in $\mathrm{K}$. Brunner and A. Meltzer, Stabilization of the Domestic and International Economy, Vol. 5 of the Carnegie-Rochester Conference Series on Public Policy (Amsterdam: North-Holland), 107-148.

Flood, Robert P. and Nancy P. Marion (1980) "The Transmission of Disturbances under Alternative Exchange-Rate Regimes With Optimal Indexing," NBER Working Paper No. 500, forthcoming in the Quarterly Journal of Economics. Gray, Jo Anna (1976) "Wage Indexation: A Macroeconomic Approach," Journal of
Monetary Economics, 2, 221-35.

Henderson, Dale W. (1981) "Balance of Payments Analysis, Fiscal Policy, and the Boyer Paper: A Comment," unpublished paper.

Marion, Nancy P. (1981) "The Exchange-Rate Effects of Real Disturbances with Rational Expectations and Variable Terms of Trade," forthcoming in the Canadian Journal of Economics.

Marston, Richard C. (1981) "Real and Monetary Disturbances in an Exchange-Rate Union," NBER Working Paper No. 705.

Modigliani, Franco and Tommaso Padoa-Schioppa (1978) The Management of an Open $\frac{\text { Economy with "100\% Plus" Wage Indexation, Essays in International Finance }}{\text { No. } 130 \text { (Princeton). }}$

Munde11, Robert A. (1963) "Capital Mobility and Stabilization Policy Under Fixed and Flexible Exchange Rates," Canadian Journal of Economics and Political Science, 29, 475-85.

Munde11, Robert A. (1964) "A Reply: Capital Mobility and Size," Canadian Journal of Economics and Political Science, 30, 421-31.

Sachs, Jeffrey (1980) "Wages, Flexible Exchange Rates, and Macroeconomic Policy," Quarterly Journal of Economics, 94, 731-47. 